\title{
Laminin Receptor 1: Can It Have a Role in Molecular Classification and Targeted Therapy of Endometrial Cancer?
}

\author{
Mertihan Kurdoglu* ${ }^{*}$
}

$\mathrm{E}$ ndometrial carcinomas which account for more than $90 \%$ of uterine cancer cases are the most common gynecologic malignancies of the female reproductive organs. Thanks to the recent molecular studies, genomic alterations leading to the pathogenesis of these types of cancers have been revealed extensively. Nowadays, conventional pathologic diagnoses of them do not seem to be able to sufficiently guide the optimal clinical managements and therefore, efforts to develop a new classification system based on their molecularmorphologic features is highly encouraged (1). Publication of the Cancer Genome Atlas (TCGA) report on a genomic analysis of 373 endometrial carcinomas (2) forced the efforts to incorporate molecular testing into routine histologic evaluation (3). Although DNA polymerase epsilon, catalytic subunit (POLE), mismatch repair (MMR), and human epidermal growth factor receptor 2 (HER2) are highly evaluated molecular tests due to potential efficacy of immune checkpoint inhibitors and other targeted therapies, the data is not sufficient to attain a clear consensus on which tests to perform (1).

Laminin receptor 1 (LAMR) which is a multifunctional protein with important roles not only in tumorcell migration and invasion but also in tumor-cell proliferation, survival, and protein translation, has been shown to be overexpressed in many malignant tumors including endometrial cancer (4-7). One of our recent studies revealed that LAMR may also have an important role in progression from premalignant to malignant state for endometrial lesions by showing disease progressionrelated gradual increment of LAMR expression in epithelial cytoplasm and basement membranes of hyperplastic endometrium with or without atypia and in cancer of endometrium (4). The results of Scheiman et al indicated that LAMR is also a potential target for gene therapy for tumor reduction and elimination, due to its regulatory role in many ways of tumor development. They also provided a novel mechanism for gene therapy in vivo, which can be used against LAMR (5).

As a conclusion, with ongoing efforts to describe the

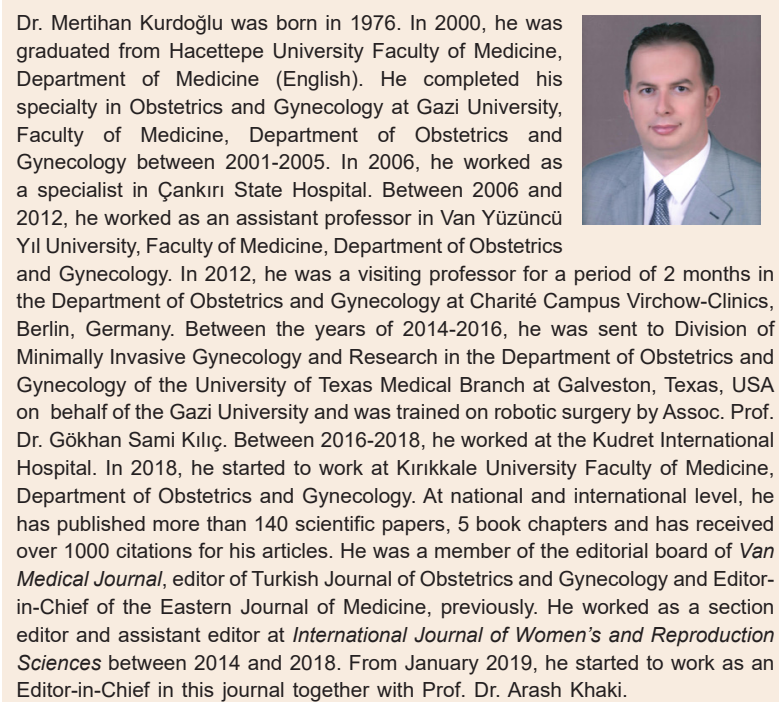
Department of Obstetrics and Gynecology. At national and international level, he has published more than 140 scientific papers, 5 book chapters and has received over 1000 citations for his articles. He was a member of the editorial board of Van Medical Journal, editor of Turkish Journal of Obstetrics and Gynecology and Editorin-Chief of the Eastern Journal of Medicine, previously. He worked as a section editor and assistant editor at International Journal of Women's and Reproduction Sciences between 2014 and 2018. From January 2019, he started to work as an Editor-in-Chief in this journal together with Prof. Dr. Arash Khaki.

current molecular landscape of endometrial cancers, it has been realised that LAMR may offer some opportunities to select personalized therapies. Further studies are warranted to clarify whether this specific molecular alterations in LAMR expression may be incorporated into the current classification systems and molecularly targeted therapies of endometrial cancer with improved patient outcomes.

\section{Ethical Issues}

Not applicable.

\section{Conflict of Interests}

The author has no conflicts of interest to disclose.

\section{References}

1. Yen TT, Wang TL, Fader AN, Shih IM, Gaillard S. Molecular Classification and Emerging Targeted Therapy in Endometrial Cancer. Int J Gynecol Pathol. 2019. doi: 10.1097/PGP.0000000000000585

2. Cancer Genome Atlas Research N, Kandoth C, Schultz N, Cherniack AD, Akbani R, Liu Y, et al. Integrated genomic 
characterization of endometrial carcinoma. Nature. 2013; 497: 67-73. doi: 10.1038/nature12113

3. Ritterhouse LL, Howitt BE. Molecular Pathology: Predictive, Prognostic, and Diagnostic Markers in Uterine Tumors. Surg Pathol Clin. 2016; 9: 405-26. doi: 10.1016/j. path.2016.04.006

4. Kurdoglu M, Kucukaydin Z, Kurdoglu Z, Bulut G, Unlu Y, Ozen S. Expression of Laminin Receptor 1 in Normal, Hyperplastic, and Malignant Endometrium. Int J Gynecol Pathol. 2018. doi: 10.1097/PGP.0000000000000535

5. Scheiman J, Tseng JC, Zheng Y, Meruelo D. Multiple functions of the 37/67-kd laminin receptor make it a suitable target for novel cancer gene therapy. Mol Ther. 2010; 18: 63-74. doi: 10.1038/mt.2009.199

6. van den Brule FA, Buicu C, Berchuck A, Bast RC, Deprez M, Liu FT, et al. Expression of the $67-\mathrm{kD}$ laminin receptor, galectin-1, and galectin-3 in advanced human uterine adenocarcinoma. Hum Pathol 1996; 27: 1185-91.

7. Faber M, Wewer UM, Berthelsen JG, Liotta LA, Albrechtsen R. Laminin production by human endometrial stromal cells relates to the cyclic and pathologic state of the endometrium. Am J Pathol 1986; 124: 384-91.

Copyright (c) 2019 The Author(s); This is an open-access article distributed under the terms of the Creative Commons Attribution License (http://creativecommons.org/licenses/by/4.0), which permits unrestricted use, distribution, and reproduction in any medium, provided the original work is properly cited. 